\title{
Global Registration Identifier for Donors
}

National Cancer Institute

\section{Source}

National Cancer Institute. Global Registration Identifier for Donors. NCI Thesaurus. Code C153369.

A unique identifier assigned to a hematopoietic progenitor cell donor, potential donor, or a cord blood product that is listed in a registry. 